\title{
Engaging undergraduate students in the Philippines in photonics research with a novel publication-driven online mentoring approach
}

Minella Alarcon, Benjamin Dingel, Annelle Chua, Aria Buenaventura, Nathaniel J. Libatique

Minella C. Alarcon, Benjamin B. Dingel, Annelle R. Chua, Aria Buenaventura, Nathaniel J. C. Libatique, "Engaging undergraduate students in the Philippines in photonics research with a novel publication-driven online mentoring approach," Proc. SPIE 11143, Fifteenth Conference on Education and Training in Optics and Photonics: ETOP 2019, 1114307 (2 July 2019); doi: $10.1117 / 12.2523856$ 


\title{
Engaging undergraduate students in the Philippines in photonics research with a novel publication-driven online mentoring approach
}

\author{
Minella C. Alarcon ${ }^{1}$, Benjamin B. Dingel ${ }^{3,4}$, Annelle R. Chua ${ }^{1}$, Aria Buenaventura ${ }^{1}$, and \\ Nathaniel J. C. Libatique ${ }^{2,4}$ \\ ${ }^{1}$ Physics Department, School of Science and Engineering, \\ Ateneo de Manila University, Quezon City, Philippines, \\ ${ }^{2}$ Electronics Computer and Communications Engineering Department, School of Science \\ and Engineering, Ateneo de Manila University, Quezon City, Philippines, \\ ${ }^{3}$ Nasfine Photonics Inc., Painted Post, NY, 14870, USA, \\ ${ }^{4}$ Ateneo Innovation Center, Ateneo de Manila University, Quezon City, Philippines
}

\begin{abstract}
This paper discusses a publication-driven, education-by-research model of engaging undergraduate students in Photonics/Optics/Physics research by requiring that all activities lead to journal publication within a year. It is based on a non-traditional university-industry collaboration arrangement that has the following unique features.

First, it utilizes offshore-based alumni (in the USA) who are active in science and technology research as mentors for the students (in the Philippines) in conjunction with the university professor advisers. We adopt inexpensive online collaboration technologies to support their virtual presence.

Second, our research topic "fuses" uniquely two separate courses of study, namely: (i) the traditional Special Relativity in Physics and (ii) the fast emerging Photonic Integrated Circuits (PICs), into an innovative research area we have called "Special-Relativity-on-a-Chip". It has the flavor of physics education combined with a taste of the latest in PICs technology. It enhances the textbook understanding of Physics/Engineering while providing potential publication opportunities.

Third, the research activities are focused mainly on modelling, simulations and design. These activities strengthen students' learning since they concentrate on and master specific mathematical/Physics/programming skills. The goal of the project is to publish 5 journal papers, and so far, (i) 3 journal papers have been published, (ii) 1 international conference paper has been accepted for oral presentation, and (iii) 3 national conference papers have been submitted for publication.
\end{abstract}

We also examine the existing research structure in the university to ensure the project's success and share best practices.

Keywords: Undergraduate Student research, online mentoring in Optics and Photonics, Physics Education

\section{INTRODUCTION}

The increasing interest for internationalization in universities has raised local awareness for global rankings of universities, where research activities and publication outputs are important considerations. Generally, publishable research results are produced by faculty advisers supported by postdoctoral fellows and advanced graduate students.

To maintain the pipeline of graduate students, there is an incentive for the faculty to encourage their undergraduate students to pursue graduate studies in science and engineering education that will lead to Science, Technology, Engineering and Mathematics (STEM)-related careers. As such, there have been strong efforts recently to encourage research with undergraduate students ${ }^{1-3}$. In the United States, the National Science Foundation sponsors programs across US universities called "Research Experience for Undergraduates (REU)"4. In these programs, undergraduate students are embedded in 
different research groups in different universities or laboratory centers within 8-10 weeks in the summer. The definite advantages of the REU programs are (i) the involvements and interactions of undergraduate students with a large number of scientific manpower of professors, scientists and researchers, (ii) the exposure to new and advanced laboratory resources and facilities, and (iii) introduction to new scientific fields and latest technical developments.

Clearly, all these are meant to provide long-lasting motivating factors for undergraduate students to pursue graduate studies, and engage in future STEM-related research activities or careers. As a first step toward research exposure for undergraduate students, the REU programs are great and must be encouraged and supported.

\subsection{Undergraduate Research in the Philippine Setting}

In the Philippine university setting, due to the limited numbers of graduate students, faculty members doing research take advantage of the opportunity to work with undergraduate students in order to increase university research output. As part of the development of university research in the Philippines in the late ' $80 \mathrm{~s}$, undergraduate students started with senior projects that have later broadened into undergraduate theses. Today, the practice is part of the university curricula with increasing emphasis on undergraduate research.

From these long-term projects, undergraduate students gain advantages from the early and intensive research involvement. It exposes them year-round to valuable research opportunities such as lecture series, research seminars, and research meetings, all of which could benefit them. First, these can broaden their knowledge and understanding of their undergraduate coursework. Second, they expose students to the research culture and how research groups operate. Lastly, they enable active students to develop deeper linkages early with research professors and graduate students.

However in order to increase university research output significantly with undergraduate students, Philippine universities are thus called to strengthen the current research practice in the following areas:

(i) Human resource capability: how to increase scientific manpower resources with minimal economic cost?

(ii) Student motivation: how to engage undergraduate students in creative ways to do optics and photonics research?

\subsection{Opportunities and Technology Enablers via Information \& Communication Technologies (ICTs)}

It is important to realize that the state of research education in the university is rapidly changing due to the massive growth in the information, telecommunication and open source technologies. Any attempts to reduce the previously mentioned research barriers for undergraduate students must incorporate these realities in order to respond effectively to the changing educational research landscape.

In particular, whether we like it or not, the traditional classroom learning model is losing its central position as the main source of knowledge acquisition and transmission. There are thousands of educational videos, online courses or lectures offered or provided by many renowned universities and institutes found in YouTube, different university websites, etc. Furthermore, today's students are exposed 24/7 to various "online connecting technologies" such as Skype, Messenger, Facebook, etc. They have access to advanced scientific materials (technical papers via open access), free simulation and programming tools (Python, Jupyter, etc), open collaborative and organizing technologies (Dropbox, Overleaf, etc).

For students, these low-cost or nearly-free information and communication technologies (ICTs) are powerful tools for knowledge acquisition. Most students develop (a) advanced programming skills, (b) digital signal processing knowledge, and (c) computer networking abilities by self-learning thru the web.

For educators and research professionals, it is a challenge to use these ICTs to eventually improve the undergraduate research program, especially in optics and photonics. These technologies are potential vehicles for knowledge creation as well as knowledge acquisition. However, the questions on how to best use them and incorporate them in undergraduate research program are still ongoing challenges. 


\section{OUR NOVEL UNDERGRADUATE RESEARCH PROGRAM}

\subsection{The PURE-ATOM Program}

As mentioned earlier, Philippine universities are called upon to develop an alternative undergraduate research program that takes into account the unique skillsets of the students and that can work around the university's limited scientific human resources and modest facilities. In particular in Ateneo de Manila University (AdMU) in order to increase its research publication output, we initiated a pilot, research program we called "Publication-driven Undergraduate Research Experience - Assisted by online Technologies and Overseas Mentoring" (PURE-ATOM for short).

PURE-ATOM is a publication-driven, result-oriented research program based on the model of "education-by-doingresearch" in engaging undergraduate students in photonics/optics/physics research. Its success is determined solely by the publication of technical journal papers, with a goal of publishing at least 3 journal papers per year. As shown in Fig. 1, PURE-ATOM is composed of three parties; (i) the overseas mentor, (ii) the undergraduate students, and (iii) the university professors, all of whom utilize the internet or the ICTs to support their long-distance communication.

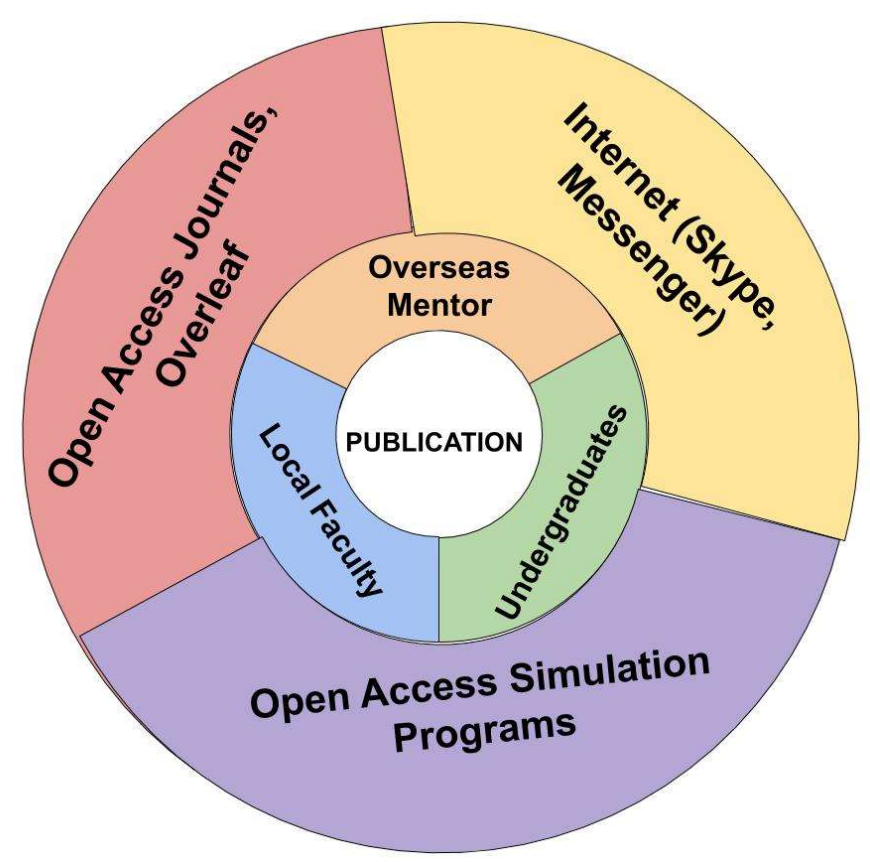

Figure 1. The model of PURE-ATOM program and its key elements.

As a research program, it recognizes three fundamental driving forces that need to be pieced together namely;

○ Undergraduate Student Motivation:

$>$ From the very start, we address the huge issue related to how to motivate and engage undergraduate students in more personal ways. The program highlights a compelling motivating factor for undergraduate students to participate by being co-authors in scientific journal article(s) that could be published in a time frame of 6 to 12 months. In fact, we believe and expect that student engagement will wane if no publishable results become evident in 6 to 9 months timeframe.

$>$ Undergraduate students have the opportunities to use their programming skills and mathematical/physics abilities, by focusing mainly on such research activities as modelling, simulations and design.

o Human Resource Enhancement:

$>$ From the very beginning, we recognize the important consideration of selecting publishable research topics. The program calls for the active participation of overseas Filipino alumni doing scientific research abroad as additional manpower resources ${ }^{5}$. They act as online research mentors in conjunction with university professors, bringing to the table their knowledge of innovative research methods and topics. The role of the mentor focuses on this issue for the program to succeed. 
$>$ The program takes advantage of the rapidly developing, nearly-free online collaborative ICTs to connect our undergraduate students with Filipino scientist/alumni abroad for undergraduate research.

$>$ Since the mentors are physically not in Philippines, these support their virtual presence economically and effectively by using the previously mentioned ICTs.

Lastly, we note a consequential but important nuance about our program. This pilot program does not give academic credits to students at the moment. All participants (overseas mentors, professors, and undergraduates students) are involved voluntarily. In particular, all three undergraduate students are doing their standard undergraduate research theses while they are engaged with our research team.

\subsection{Program Proper}

The research program started in August 2017 with weekly online meetings between Ms. Buenaventura (AdMU undergraduate student) and Dr. Dingel (AdMU alumnus). The current participants are:

- Mentor and Lead Organizer:

Dr. Benjamin B. Dingel from Nasfine Photonic Inc. based in New York, USA, and is also affiliated with the Ateneo Innovation Center (AIC, a research center within the AdMU's structure) as Research Scientist Fellow. He is also Senior Editor of SPIE's Optical Engineering Journal and has chaired different SPIE Photonics conferences. He was also an external thesis adviser for students at City College of New York City, The City University of New York (CCNY-CUNY), and Binghamton University- The State University of New York.

- Academic Faculty:

Dr. Minella Alarcon is now affiliated with the Physics Department of AdMU. She is a retired UNESCO Senior Programme Specialist for Science Education and was a recipient of the 2011 SPIE Education Award.

Dr. Nathaniel Libatique is Associate Professor of the Electronics Computers \& Communications Engineering Department, AdMU, and is also Research Scientist with the Ateneo Innovation Center. He is the Director of the PLDT-Ateneo Advanced Network Testbed and leads the Networked Systems Lab of the School of Science and Engineering. He is currently Principal Investigator of several research projects and testbeds on distributed fiber sensor systems, IoT data driven systems, among others. He is currently Associate Editor of the SPIE Optical Engineering Journal.

- Undergraduate Students:

Mr. Katsuya Akamatsu - $4^{\text {th }}$ year undergraduate student (Physics Department)

Miss Aria Buenaventura $-4^{\text {th }}$ year undergraduate student (Physics Department),

Miss Annelle Raphayette Chua - $5^{\text {th }}$ year undergraduate student (Physics Department)

\subsubsection{Overseas Research Mentor}

The overseas research mentor has three key roles. First, he provides the faculty and students unique research opportunities that cannot be found within their university. He brings his expertise in optics and photonics and proposes appropriate research topics in consultation with the local advisers in the university. Besides that, he may also give additional resources (e.g. journal articles, learning materials, software) and can contact his own colleagues to aid the progress of the project. Second, he acts as a mentor to the students under him, organizing weekly, one-on-one, online meetings with the students. He guides the students in their research work, setting them to tasks that both enrich their understanding of key concepts and contribute to the manuscript being written. Lastly, he, along with the participating local faculty, determines the research focus of the whole group and drives the pace of its activities.

At present, this research group is led by the overseas mentor; however, the leadership of this group is eventually expected to be passed on to the local faculty. 


\subsubsection{University Faculty}

Prior to the project, the faculty scouts out prospective students whose capabilities and interests they are familiar with. During the project, the faculty acts as the group's liaison with the Physics department. As they are recognized employees of the university and have worked with the department for many years, they can ensure that the research group does not deviate from these protocols and, additionally, can grant students access to university facilities for research purposes.

Besides those, the professors also share two of the overseas research mentor's key roles: i) mentorship of the students in the group and ii) research partner. The professors, with the overseas research mentor, must draft a research plan that can utilize and enrich the talents of their prospective students. As they have known these students for a longer time, they can offer an informed assessment of the students' abilities and progress. Like the overseas research mentor, the professors may also guide the students in their research work. As co-research heads, the professors and the overseas research mentor must collaborate on a higher technical level to further develop the research work. They must ensure that their research plan maximizes the research opportunities and considers the conditions of the students and the university.

\subsubsection{Undergraduate Students}

At present, the students are senior physics majors. It is important to note that while undergraduate students may only have limited knowledge of new research technologies, they would have other important skills not yet known to teachers/scientists waiting to be drawn out by active research involvement. As such, this program attempts to encourage the participating students to play a more active role as research partners to the mentor and the local faculty. The students' activities will be discussed in detail in Section 4.

\section{RESEARCH TOPIC SELECTION AND CONSIDERATIONS}

It is a well-known fact that the biggest problem for any researcher is finding a publishable research topic. A good technical research topic must not only be new and relevant but also not-yet-fully investigated so that any researcher has a good chance to study it further, perform simulations, conduct experiments, and arrive at worthy conclusions. Since our program's aim is to publish technical journal paper(s) within a 9 to 12 month timeframe, this narrows down immediately our research focus to the following, namely:

- Simulation-focused research that involves modeling, design, signal processing, analysis, and theory because the basic scientific software tools are available to the undergraduate students.

- Photonics Integrated Circuits (PICs)-focused research because of the mentor's strong familiarity with the subject area and his knowledge of what is publishable or not in this field.

- "Scientific analogue-focused" or optical analogue-focused research within the PICs' broadened area where properties of the PICs are "related or connected" to subject matters in the physics courses that the undergraduate students are studying or have studied in their traditional physics courses.

These "simulation-centric research activities" have the following advantages within the Philippine research environment. First, these research activities require only computer to conduct the research. As such, we can operate under a low-cost research structure and start our research activities immediately. Second, it utilizes undergraduate students' advanced programming and modelling skills for research purposes.

Presently, PICs offer an active research area in optics and photonics technical community because of its wide applications in many fields. Thus, this area provides a solid foundation where other research topics could emerge from. Because of its novelty and versatility, PICs can potentially be linked to phenomena studied in a totally different field in physics or engineering and serve as an optical analogue to these phenomena. We look for a "knowledge-connection" that is not yet known so that we can focus on it, develop it, extend it, and then publish it.

\subsection{Niche Research Area-Special-Relativity-on-a-Chip}

Given the above considerations, we selected the topic that "fuses" uniquely two separate courses of study, namely: (i) the traditional Special Relativity (SR) in Physics and (ii) the fast emerging Photonic Integrated Circuits (PICs). In other words, our "niche research area" is the optical analogues of the phenomena in SR using the PICs. By applying the established technology or concept in PICs onto SR to reach novel research insights, we establish a strong "link" (or optical analogue) between (i) some of the phenomena and concepts in SR, and (ii) the amplitude, phase, and intensity responses of the 
microring resonators (MRRs)-based photonic integrated circuits (PICs). We refer to this innovative optical analogue research area as the "Special-Relativity-on-a-Chip" for short. Fig. 2 depicts the general overview of our niche research area we referred to as the Special-Relativity-on-a-Chip.

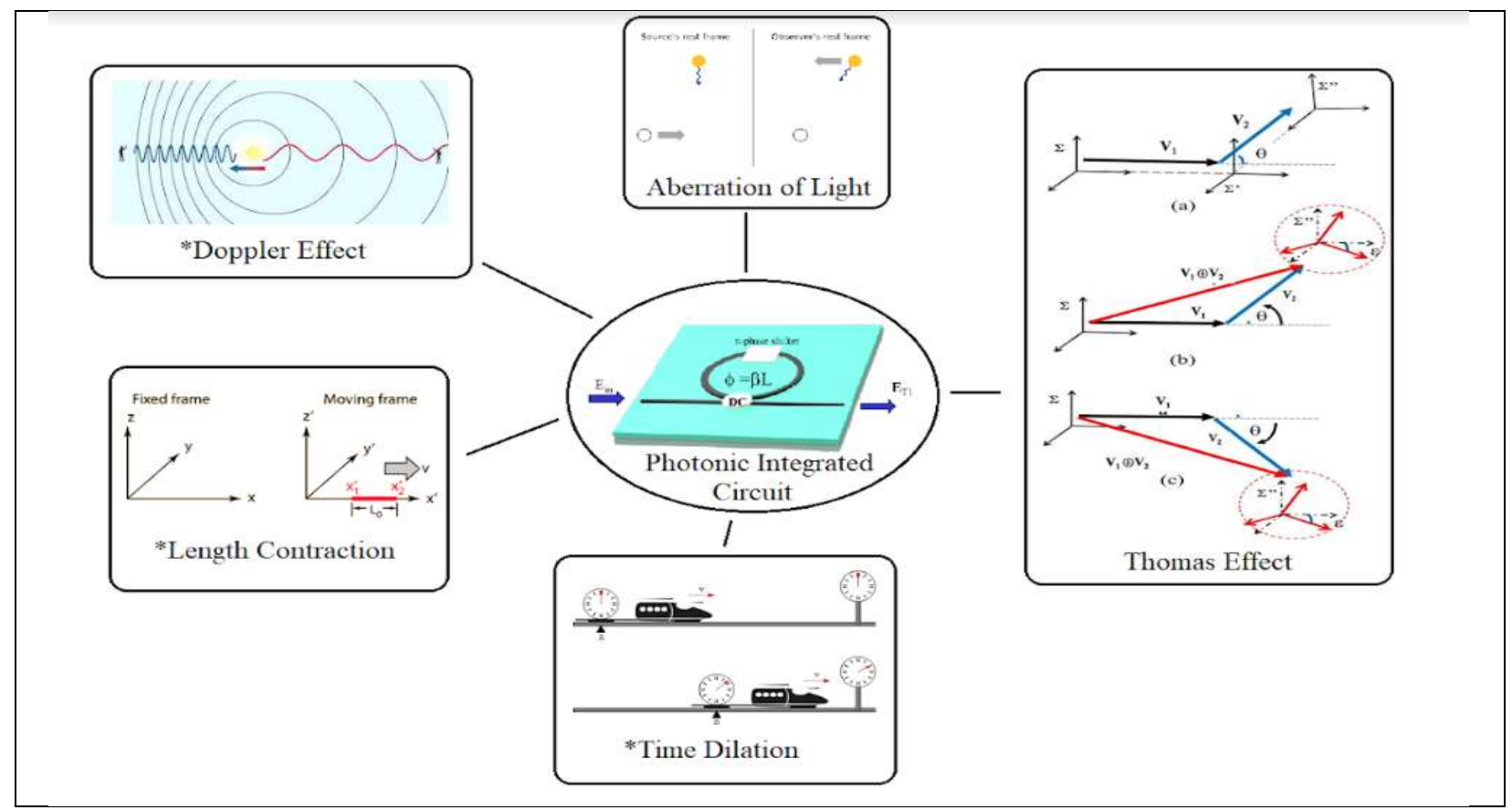

Figure 2. Pictorial diagrams of the SR phenomena that can be linked to PICs.

In this research area, we first researched, established and reported, for the first time to the best of our knowledge, an optical analogue between the Thomas rotation angle effect found in SR, and the phase response of an optical All-Pass Filter (APF) in Photonic Integrated Circuits, (PICs) ${ }^{6}$. The Thomas Effect is one of the counter-intuitive phenomena in SR while the APF is one of the key building blocks in PICs. Then, we introduced another optical analogue for the Einstein Velocity Addition (EVA) ${ }^{7}$ which utilized an optical add-drop-filter (OADF), another key building block in PICs. This particular analogue is significant because EVA is one of the key concepts in SR that underlie many relativistic effects. Most recently, we reported a photonic circuit analogue of the relativistic aberration of light (AL) phenomenon in SR using an All-Pass Filter (APF) ${ }^{8}$. Mathematically speaking, it is based on the close similarity between (i) the equation of the EVA in the complex plane formulation for SR, and (ii) the equation of the complex electric field output signal from a coupled microring resonator (MRR)-based PICs.

It is the goal of this project to publish papers on still unreported optical analogues of SR phenomena. We plan to validate known SR phenomena and probe still unexplored aspects of SR. With PICs as a platform, potential SR experiment can be achieved not in a large and bulky laboratory setting but with a 'laboratory-on the-chip' platform. It will open doors for many researchers to pursue experimental investigations of SR phenomena without the need for expensive and bulky laboratory setups for such endeavors.

\section{STUDENT RESEARCH ACTIVITIES}

The tasks set for students over the course of the research project can be grouped into four categories: i) Technical Learning curve (paper-reading, literature review, and mathematical theory and practice), ii) Modeling and Simulation, iii) Manuscript Production and Submission, and iv) Conference Presentation

\subsection{Technical Learning}

The students' participation is significant and includes reading scientific papers, verifying mathematical equations, sharing their ideas and opinions on technical issues, and doing calculations and simulations. 
For the first part of the project, students need to have a basic grasp of the topic before they can engage with the problem set by the mentor/professor. As such, their first few days involve some digging into current literature, either from the references of their mentors or from their own searches. The overseas mentor compiled a database of technical papers for students to read. For the photonic-chip projects, the students read up on key papers on Einstein Velocity Addition as this served as the backbone to the many potential papers the mentor planned to publish. This gives them an opportunity to familiarize themselves with the relevant concepts to get them started with the project. Discussions with the mentor around the subject are encouraged so students can ask for guidance on the areas they have trouble understanding. This gives students a chance to absorb the material further and clear up any confusion.

After the students have had just enough background on the topic, they are then tasked to wrestle with the mathematics of the topic. This may involve further discussion on essential equations derived from past literature and review on physical mathematics techniques taught in their university coursework. Students are then tasked to attempt deriving the relevant equations set forth by the mentor starting from those provided in literature. This achieves three goals: 1) gives students a real life application of the mathematical skills they learned in their coursework, 2) verifies the key equations to be used in the paper, and 3) lets the overseas mentor know how detailed the equation derivation should be in the future paper for a general audience to understand.

\subsection{Modeling and Simulation}

The discussions with mentors help the students start on modeling and simulating. Armed with the necessary mathematical knowledge, students are to use a program (such as Python or Mathematica) to simulate the behavior of a given phenomenon and plot the results for discussion. They are then tasked to interpret these results and mine for insights along with the mentor. This task gives students the opportunity to hone their skills on programming and familiarize themselves with numerical methods in solving problems. It also challenges their creativity and communication skills in designing succinct and coherent graphs for an audience.

\subsection{Manuscript Production and Submission}

Students are then tasked to coordinate with the overseas mentor in writing the manuscript based on the results of their simulation. This is the culmination of their research work in a particular project. Writing involves rehashing and synthesizing various information from previous discussions, giving students the opportunity to attain a more in-depth understanding of the subject. In particular, students may also be tasked to edit, draw figures and tables, perform experiments if necessary, write and revise manuscripts, and proofread manuscripts from fellow students and the overseas mentor before attempting to write their own. As a learning opportunity, this gives them a chance to observe the process of writing a manuscript and lets them practice their writing skills. As a contribution to the research group, this activity allows the main writers to gauge the coherence of their writing and catch grammatical errors before submission. Since multiple papers can be generated from a worthwhile research topic, there is a potential for students to contribute to many publications during the project.

Fig. 3 shows a Gantt chart of the breakdown of research activities involved in manuscript preparations, providing an idea of the students' work schedule. In the first paper, students spend the largest portion of their time delving into the topic via knowledge acquisition and skills training. Simulation and modelling take the second largest portion. However, in the succeeding papers, the time spent on these two areas decreases as students gain more competency in their given topic of interest. Meanwhile, writing and revising the manuscript take the same amount of time in all papers.

\subsection{Conference Presentation}

Lastly to complete the experience of the students as researchers, they are encouraged to present their works in either national or international technical conferences, as first authors. In section 5, we report that all three students have submitted their latest research works in a national conference which will be presented in May 2019. Table 1 summarizes all the students' research tasks, their corresponding outputs, and the learning outcomes. 


\begin{tabular}{|c|c|c|c|c|c|c|c|c|c|c|c|c|c|c|c|c|}
\hline & Month & 1 & 2 & 3 & 4 & 5 & 6 & 7 & 8 & 9 & 10 & 11 & 12 & 13 & 14 & 15 \\
\hline \multirow{4}{*}{ Paper \#1 } & Technical Learning Curve & & & & & & & & & & & & & & & \\
\hline & Modeling and Simulation & & & & & & & & & & & & & & & \\
\hline & Manuscript Production & & & & & & & & & & & & & & & \\
\hline & Manuscript Submission & & & & & & & & & & & & & & & \\
\hline \multirow{4}{*}{ Paper \#2 } & Technical Learning Curve & & & & & & & & & & & & & & & \\
\hline & Modeling and Simulation & & & & & & & & & & & & & & & \\
\hline & Manuscript Production & & & & & & & & & & & & & & & \\
\hline & Manuscript Submission & & & & & & & & & & & & & & & \\
\hline \multirow{4}{*}{ Paper \#3 } & Technical Learning Curve & & & & & & & & & & & & & & & \\
\hline & Modeling and Simulation & & & & & & & & & & & & & & & \\
\hline & Manuscript Production & & & & & & & & & & & & & & & \\
\hline & Manuscript Submission & & & & & & & & & & & & & & & \\
\hline \multirow{4}{*}{ Paper \#4 } & Technical Learning Curve & & & & & & & & & & & & & & & \\
\hline & Modeling and Simulation & & & & & & & & & & & & & & & \\
\hline & Manuscript Production & & & & & & & & & & & & & & & \\
\hline & Manuscript Submission & & & & & & & & & & & & & & & \\
\hline
\end{tabular}

Figure 3. Gantt chart of tasks given to students for each paper.

Table 1. Research tasks performed by undergraduate students.

\begin{tabular}{|c|l|l|l|}
\hline Research Task & \multicolumn{1}{|c|}{ Details } & Research Output & \multicolumn{1}{|c|}{$\begin{array}{c}\text { Students' Learning } \\
\text { Outcomes }\end{array}$} \\
\hline $\begin{array}{c}\text { Paper reading } \\
\text { and discussion }\end{array}$ & $\begin{array}{l}\text { - Perusal of relevant literature to the project's } \\
\text { research topic. } \\
\text { - Discussion of the topic for questions and } \\
\text { clarifications with the overseas mentor. }\end{array}$ & $\begin{array}{l}\text { Report summarizing } \\
\text { key findings of paper/s }\end{array}$ & $\begin{array}{l}\text { - Familiarization with the } \\
\text { literature of the topic } \\
\text { - In-depth understanding of } \\
\text { key concepts }\end{array}$ \\
\hline $\begin{array}{c}\text { Verification of } \\
\text { equations and } \\
\text { proofs }\end{array}$ & $\begin{array}{l}\text { Attempts to derive certain equations based on } \\
\text { equations from literature. }\end{array}$ & $\begin{array}{l}\text { Derivation of key } \\
\text { equation }\end{array}$ & $\begin{array}{l}\text { Practice and application of } \\
\text { physical mathematics skills } \\
\text { attained in their coursework }\end{array}$ \\
\hline $\begin{array}{c}\text { Modeling and } \\
\text { simulation }\end{array}$ & $\begin{array}{l}\text { - Usage of mathematical software (e.g. } \\
\text { Python) to simulate a phenomenon. } \\
\text { - Discussion of the results and their insights } \\
\text { with the overseas mentor. }\end{array}$ & $\begin{array}{l}\text { Graphs, key insights } \\
\text { and behaviors }\end{array}$ & $\begin{array}{l}\text { - Practice on programming } \\
\text { skills } \\
\text { - Better understanding of the } \\
\text { phenomenon }\end{array}$ \\
\hline $\begin{array}{c}\text { Editing of in- } \\
\text { progress } \\
\text { manuscripts }\end{array}$ & $\begin{array}{l}\text { - Proofreading of other students' } \\
\text { - Critique of its coherence } \\
\text { - Make tweaks to highlight key insights }\end{array}$ & $\begin{array}{l}\text { Refined paper, } \\
\text { publication }\end{array}$ & $\begin{array}{l}\text { Surface understanding of the } \\
\text { topic at hand were attained. }\end{array}$ \\
\hline $\begin{array}{c}\text { Writing of } \\
\text { manuscript }\end{array}$ & $\begin{array}{l}\text { Significant contribution to the writing of a } \\
\text { journal publication }\end{array}$ & Paper for publication & $\begin{array}{l}\text { Holistic and in-depth } \\
\text { knowledge of the subject. }\end{array}$ \\
\hline $\begin{array}{c}\text { Conference } \\
\text { Presentation }\end{array}$ & $\begin{array}{l}\text { - Mock presentations to the research group } \\
\text { - Presentation to an audience or a panel }\end{array}$ & Presentation & $\begin{array}{l}\text { Improvement of presentation } \\
\text { and communication skills }\end{array}$ \\
\hline
\end{tabular}




\section{RESEARCH OUTPUT}

\subsection{Preliminary Research Outputs}

With this mode of mentoring and with the research program being publication-driven, we have aggressively conducted research that could lead to publishable research results. The number of our publications has increased rapidly after our initial, one-year foundational research on Special-Relativity-on-a-Chip from August 2017 to August 2018. From August 2018 to February 2019, we have researched, explored, and developed other aspects of Special-Relativity-on-a-Chip and submitted them for publication accordingly.

Table 2 summarizes our published, accepted and submitted papers for technical journal, international conference, and domestic conferences. At the time of this manuscript submission, so far, we have (i) 3 published journal papers, 1 submitted journal paper, (ii) 1 accepted paper for international conference (this conference), and (iii) 3 accepted/submitted manuscripts for national conference ${ }^{6-13}$.

Table 2. Preliminary publication results of the research program.

\begin{tabular}{|c|c|c|c|}
\hline Publisher & Title & Status & Ref \\
\hline \multicolumn{4}{|l|}{ Journal Paper } \\
\hline Journal of Modern Optics & $\begin{array}{l}\text { Optical Analogue between Relativistic Thomas Effect in Special } \\
\text { Relativity and Phase Response of Photonic Integrated Circuits-based } \\
\text { All-Pass Filter (APF) }\end{array}$ & $\begin{array}{l}\text { Published, } \\
\text { Aug } 2018\end{array}$ & 6 \\
\hline Journal of Modern Optics & $\begin{array}{l}\text { Towards Special-Relativity-on-a-Chip: Analogue of Einstein Velocity } \\
\text { Addition using Optical Add-Drop Filter (OADF) }\end{array}$ & $\begin{array}{l}\text { Published, } \\
\text { Jan } 2019\end{array}$ & 7 \\
\hline $\begin{array}{l}\text { Optik - International } \\
\text { Journal for Light and } \\
\text { Electron Optics }\end{array}$ & $\begin{array}{l}\text { Relativistic Aberration of Light Mimicked by Microring Resonator- } \\
\text { based Optical All-Pass Filter (APF) }\end{array}$ & $\begin{array}{l}\text { Published, } \\
\text { Feb } 2019\end{array}$ & 8 \\
\hline Optics Communication & $\begin{array}{l}\text { Thin Film-based Gires-Tournois Resonator (GTR) as Quasi-Optical } \\
\text { Analogue of the Thomas Angle Rotation in Special Relativity }\end{array}$ & $\begin{array}{l}\text { Submitted, } \\
2019\end{array}$ & 9 \\
\hline \multicolumn{4}{|l|}{ International Conference } \\
\hline $\begin{array}{l}\text { ETOP - Education and } \\
\text { Training in Optics \& } \\
\text { Photonics Conference } \\
\end{array}$ & $\begin{array}{l}\text { Engaging Undergraduate Students in the Philippines in Photonics } \\
\text { Research with a Novel Publication-Driven Online Mentoring Approach }\end{array}$ & $\begin{array}{l}\text { Accepted, } \\
\text { Feb } 2019\end{array}$ & $\begin{array}{c}10 \\
\text { (this } \\
\text { paper) }\end{array}$ \\
\hline \multicolumn{4}{|l|}{ Domestic Conference } \\
\hline \multirow{3}{*}{$\begin{array}{l}37^{\text {th }} \text { Annual Conference of } \\
\text { Samahang Pisika ng } \\
\text { Pilipinas (SPP) }\end{array}$} & $\begin{array}{l}\text { Photonic chip-based analogue of the Thomas Effect in Special } \\
\text { Relativity: Important design consideration }\end{array}$ & $\begin{array}{l}\text { Accepted, } \\
\text { Apr } 2019\end{array}$ & 11 \\
\hline & $\begin{array}{l}\text { Cross-coupled Parallel Microring Resonators and Its Comparison to } \\
\text { Coupled-Resonator Induced Transparency }\end{array}$ & $\begin{array}{l}\text { Submitted, } \\
\text { Apr } 2019\end{array}$ & 12 \\
\hline & $\begin{array}{l}\text { Thin Film-based Optical Analogue of a Phenomenon in Special } \\
\text { Relativity Known as the Thomas Effect }\end{array}$ & $\begin{array}{l}\text { Submitted, } \\
\text { Apr } 2019\end{array}$ & 13 \\
\hline
\end{tabular}

\subsection{Impacts of Special-Relativity-on-a Chip}

As a research topic for undergraduate students, this topic does not require too much in-depth immersion for students since most of them have encountered the key concepts of SR earlier in their student life. Furthermore, students are also intellectually challenged with the simulation, mathematics and analytical tasks involved in these research topics.

As a topic for researchers in the Philippine setting, this is advantageous and appropriate because we do not need to replicate or conduct many expensive research activities in order to address technical issues in both SR and PICs. Rather the research challenge is to find innovative ways to use existing techniques and apply them to both fields.

Lastly, as a research area in general, Special-Relativity-on-a-Chip is a rich resource with a potential to generate more publication outputs. For one, there is a need to research and develop "building blocks" for different SR phenomena that can be interconnected and/or combined to model a more advanced SR system. It is well-known that richer and bizarre SR behaviors are produced (such as the Penrose-Terrell effect and the relativistic beaming effect) when different relativistic effects are combined. Furthermore, there is also a need to research "building blocks" that are multi-purpose that can be applied to multiple SR phenomena without too much complicated re-engineering efforts. Such building block is optimal and cost-effective. These challenges promise to make Special-Relativity-on-a-Chip a potentially active research area. 


\section{TECHNOLOGY ASSESSMENT}

In this section, we highlight the technologies we utilized in this long-distance research effort. We scanned available technologies that could enable our work and have decided on mix of technologies in our stack because they fulfill certain essential requirements. We choose free and/or open source software, or free versions of paid software platforms to enable our work. However, we also use best of breed software even in its paid form whenever its use is required to produce quality and timely work. Table 3 lists these technologies that serve as vital infrastructure for our research efforts.

Table 3. The technology stack, the products, its useful features, and recommended features to enhance the productivity.

\begin{tabular}{|c|c|c|c|}
\hline Technologies & Products & Useful Features & $\begin{array}{l}\text { Needed Features } \\
\end{array}$ \\
\hline $\begin{array}{l}\text { Video } \\
\text { Conferencing and } \\
\text { Texting Tools }\end{array}$ & Skype, Messenger & $\begin{array}{l}\text { Decent network which provides a } \\
\text { stable internet connection }\end{array}$ & $\begin{array}{l}\text { Other features like group video \& } \\
\text { screen share are only available after a } \\
\text { fee }\end{array}$ \\
\hline \multirow[t]{2}{*}{ Cloud Storage } & Google Docs & $\begin{array}{l}\text { Users can simultaneously edit a } \\
\text { document }\end{array}$ & $\begin{array}{l}\text { Cannot handle equations and certain } \\
\text { limitations to word processing } \\
\text { functionality }\end{array}$ \\
\hline & Dropbox & $\begin{array}{l}\text { Users can share documents and } \\
\text { journal articles with each other }\end{array}$ & $\begin{array}{l}\text { Storage of more than } 1 \mathrm{~GB} \text { requires a } \\
\text { fee }\end{array}$ \\
\hline \multirow{2}{*}{$\begin{array}{l}\text { Modelling and } \\
\text { Simulation Tools }\end{array}$} & Mathematica & $\begin{array}{l}\text { Interactive parameter manipulation } \\
\text { and dynamic data visualization }\end{array}$ & Software version mismatch \\
\hline & Python (Jupyter) & $\begin{array}{l}\text { Well-documented open source tool } \\
\text { with dynamic data visualization }\end{array}$ & Occasional package incompatibility \\
\hline \multirow[b]{2}{*}{$\begin{array}{l}\text { Collaborative } \\
\text { Editing Tools }\end{array}$} & MS Word & Commonly found in personal devices & N/A \\
\hline & Overleaf (LaTEX) & $\begin{array}{l}\text { Better support on equation and figure } \\
\text { handling and creation of publication- } \\
\text { worthy documents }\end{array}$ & $\mathrm{N} / \mathrm{A}$ \\
\hline $\begin{array}{l}\text { Internet Speed, } \\
\text { Fiber Wireless }\end{array}$ & Local ISP provider & $\begin{array}{l}\text { Certain locations in the university has } \\
\text { an internet bandwidth greater than } 3 \\
\text { Mbps, sufficient for a video } \\
\text { conference }\end{array}$ & $\begin{array}{l}\text { Easier access to areas in the university } \\
\text { with sufficient bandwidth for students } \\
\text { and faculty }\end{array}$ \\
\hline
\end{tabular}

\subsection{Video Conferencing}

For video conferencing, we chose Skype over other commonly available services such as Facebook Messenger, Google Hangout, Viber or Zoom. Zoom and others in its class require a paid subscription. In particular Messenger could not handle our video feeds and does not have sufficiently consistent audio quality over the course of meetings that extend over 1 to 2 hours, while the participants are not sufficiently familiar with the other mentioned services. Critically, most of us had Skype installed in our handsets, tablets and computers, and had found that Skype's algorithm is able to handle conference call attendees with sufficiently good audio quality even if the connection is supported only through heavily utilized LTE and 4G links. The screen sharing option was especially useful in certain discussions where sensitive documents need to be shared temporarily for the purposes of making a point without having to use up bandwidth to be sent as an email attachment or permanently shared via a cloud storage service.

\subsection{Cloud Storage}

Dropbox and Google Drive were chosen for the quality of the sharing service and its ubiquity as a sharing option in many software and apps in multiple devices.

\subsection{Modelling and Simulation Tools}

For our modelling and simulation we heavily relied on Mathematica because of its large library of symbolic and numerical computation commands and the full control over figures and graphs. Python was also of great use, especially in the open source notebook platform, the Jupyter Notebook environment, which closely parallels the Wolfram notebook paradigm espoused by Mathematica. The Jupyter Notebook has a distinct capability of integrating markdown as well as Latexformatted equations in the document (Latex rendering is cumbersome in Mathematica, and is only available in certain paid software, such as Quiver in the Mac OS X environment), in addition with images and python code, which can be executed interactively much like in Mathematica. 


\subsection{Collaborative Editing Tools}

For collaborative editing, we had found that the conventional draft and comment workflow still works, so there was no need for real-time collaborative editing engines such as that provided by the Google Docs platforms, certainly no need for paid or subscription services along those lines. The Microsoft Word versioning capabilities were very useful to distinguish between multiple versions, which in our work run in our workflow from 10 to 30 versions in a typical draft to final manuscript production. Recently, because of its superior typesetting, easy to use equation numbering and figure placement, the quick ability to re-order the flow of a paper via automated section numbering, and the ready option to submit paper formats in Latex, we have chosen the Latex engine as a viable manuscript production engine in our workflow. To lighten the need for custom desktop setups, and to circumvent the possibility of the system breaking due to updates, we use the free versions of the Overleaf online Latex editing platform. An online service takes care of updates automatically, leaving the user free to concentrate on the document rather than on software installation and dependencies, and the variety of flavors across windows, Linux and OS X platforms. Overleaf also enables easy sharing via the sending of document links, device-independent editing and has the capability for document version numbering.

\subsection{Internet Speed, Fiber Wireless}

Because of the ubiquitous availability of internet bandwidth across multiple devices and locations and the pressure of multiple engagements and partners that are aware of these capabilities we often find ourselves trying to meet under these constraints and to work our schedules around school, lecture and administrative demands. Time zone considerations also play a factor in our choice of meeting time and location - hence impacting internet service quality. In particular we have utilized wireless broadband via handsets $(3 \mathrm{G}, 4 \mathrm{G}$, LTE), fixed school wireless connections, and home broadband connections (fiber or DSL or fixed wireless) whenever or wherever our schedules permit.

\section{ISSUES ENCOUNTERED and RECOMMENDATIONS}

At every stage of the research project, we faced certain issues and problems related to human resources and communication technologies. However, we make do with whatever is available for students, mentor, and professors. Table 4 lists these issues and problems in summary form. We address these issues with some simple and doable recommendations to further extend the gains of this program. Briefly, our recommendations are grouped according to (i) student support, (ii) faculty and mentor support, and (iii) scaling up support.

Table 4. A table on the difficulties and issues faced by the members of the research group.

\begin{tabular}{|l|l|}
\hline Focus on & Issues \\
\hline \multirow{2}{*}{ Undergraduate Students } & Time constraints \\
\cline { 2 - 2 } & Lack of student credit \\
\hline Professors and Mentors & Time constraints \\
\hline \multirow{2}{*}{ Communication Infrastructure } & Poor internet connection \\
\cline { 2 - 2 } & Limited resources \\
\hline Funding & Lack thereof \\
\hline
\end{tabular}

\subsection{Student Support}

First, to support more students to conduct publishable papers, we suggest building simple structural changes like (i) creating a "Dean's List" for students who published in journals and conferences per semester just like the traditional Dean's List which is based on academic grades, (ii) creating a grading system where student earns academic credit or pointequivalent per journal publication, and (iii) providing incentives for students to turn their undergraduate's thesis into journal/conference publication.

\subsection{Faculty and Mentor Support and Scaling Up Support}

Second, it would be advisable if some form of "class deloading credit" is provided to faculty members participating in these pilot research activities, since one of the most important problems is the time constraints of faculty members. Third, it would be helpful if the university integrated this pilot program into an existing research program within the university structure with some budgetary resources. Matching program to generate more "Mentor-Professor-Student" teams is necessary. This will allow the program to scale up. 


\section{CONCLUSION}

We reported a pilot undergraduate research program PURE-ATOM that is aimed at engaging undergraduate students of the Ateneo de Manila University in the Philippines in photonics research. Three key elements of the program are (i) coauthorship of journal papers with students as a motivating factor, (ii) the utilization of the rapidly changing information and communication technologies, and (iii) the participation of overseas mentors.

The publication-driven nature of the PURE-ATOM, together with the massive collaborative tools available, is changing not only the way students learn, read, and absorb "old" traditional materials but also how undergraduate research is being conducted. As evidenced by our work, we have (i) 3 published and 1 submitted journal papers, (ii) 1 accepted paper for international conference, and (iii) 3 submitted manuscripts for national conference within 1.5 year time frame.

\section{ACKNOWLEDGMENTS}

The financial assistance for conference participation from the Physics Department BCA Endowed Fund, and the Ateneo de Manila University is greatly appreciated.

\section{REFERENCES}

[1] Madan, C. R. and Teitge, B. D., “The Benefits of Undergraduate Research: The Student's Perspective,” PennState Division of Undergraduate Studies, 1 May 2013, <https://dus.psu.edu/mentor/2013/05/undergraduate-researchstudents-perspective/> (30 April 2019).

[2] Gentile, J., Brenner, K. A. and Stephens, A., [Undergraduate Research Experiences for STEM Students: Successes, Challenges, and Opportunities], National Academies Press, Washington D.C. 69-96 (2017).

[3] Hathaway, R. S., Nagda, B. A. and Gregerman S. R., "The relationship of undergraduate research participation to graduate and professional educational pursuit: an empirical study," Journal of College Student Development 2002(43), 614-631 (2002).

[4] "Research Experiences for Undergraduates (REU)," National Science Foundation, $<$ https://dus.psu.edu/mentor/2013/05/undergraduate-research-students-perspective/> (30 April 2019).

[5] Jallorina, M. P. A., Culaba, I. B., Alarcon, M., Simpas, J., Aranas, E. B. and Dingel, B. B., "Cyber research mentoring in science in Philippine private universities: Leveraging online collaboration technologies and offshorebased alumni," ESJ 4, 212-221 (2013).

[6] Dingel, B. B., Buenaventura, A. and Murakawa, K., "Optical analogue between relativistic Thomas effect in special relativity and phase response of the PICs-based APF," J. Mod. Opt 65(19), 2171-2178 (2018).

[7] Dingel, B. B., Buenaventura, A., Chua, A. R. and Libatique, N. J. C., "Toward Special-Relativity-on-a-Chip: analogue of Einstein velocity addition using optical add-drop filter (OADF)," J. Mod. Opt 66(6), 679-688 (2019).

[8] Dingel, B., Buenaventura, A., Chua, A. R., Libatique, N. J. C. and Murakawa, K., "Relativistic aberration of light mimicked by microring resonator based optical All-Pass Filter (APF)," Optik 183(2019), 82-91 (2019).

[9] Dingel, B., Buenaventura, A., Chua, A. and Libatique, N., "Thin Film-based Gires-Tournois Resonator (GTR) as Quasi-Optical Analogue of the Thomas Rotation Angle Effect in SR", Optics Comm., (Under Review).

[10] Alarcon, M., Dingel, B. B., Libatique, N., Buenaventura, A. and Chan, A., "Engaging Undergraduate Students in the Philippines in Photonics Research with a Novel Publication-Driven Online Mentoring Approach", SPIE ETOP (Education and Training in Optics \& Photonics) Conference, Quebec, Canada, May 2019.

[11] Buenaventura, A., Chua, A., Akamatsu, K. and Dingel, B., "Photonic chip-based analogue of the Thomas Effect in Special Relativity: Important design consideration", The 37th Samahang Pisika ng Pilipinas International Physics Conference and Annual Meeting, Bohol, Philippines, May 2019, (Accepted).

[12] Akamatsu, K., Dingel, B., Buenaventura, A. and Chua, A., "Cross-Coupled Parallel Microring Resonators (MRRs) and its Comparison to Coupled-Resonator Induced Transparency", The 37th Samahang Pisika ng Pilipinas Int'1 Physics Conf. and Annual Meeting, Bohol, Philippines, May 2019, (Under Review).

[13] Chua, A., Dingel, B., Buenaventura, A. and Akamatsu, K., "Thin-Film based Analogue of a Phenomenon in Special Relativity known as Thomas Effect", The 37th Samahang Pisika ng Pilipinas Int'l Physics Conference and Annual Meeting, Bohol, Philippines May 2019, (Under Review). 